\title{
Understanding Motivations: Exploring Adolescents Perceptions and Experiences of Physical Activity-Nutrition Program
}

\author{
Jenifer Li ${ }^{1}$, Nancy Fenton ${ }^{2, *}$, Stephanie Thayer ${ }^{1}$, Caryl Russell ${ }^{1}$, Monica Gray ${ }^{3}$ \\ ${ }^{1}$ Department of Kinesiology, University of Waterloo, Canada \\ ${ }^{2}$ School of Public Health and Health Systems, University of Waterloo, Canada \\ ${ }^{3}$ Patient Care Solutions, Canada
}

Copyright (C) 2015 Horizon Research Publishing All rights reserved.

\begin{abstract}
The increasing rate of obesity among children and youth is a major health concern for the Canadian population. Although exercise-based intervention programs have shown significant improvements in clinical markers, maintenance and management of these improvements are often stunted or reversed due to barriers relating to negative attitudes and lack of motivation towards exercise. The Self-Determination Theory suggests a shift in motivation towards physical activity, from lack thereof to autonomous, can occur within supportive environments. It is thus crucial to explore the perceptions and experiences of overweight adolescents enrolled in fitness-nutrition programs. This research attempts to go beyond the biophysical markers of health to provide insight on individual experiences that affect attitudes towards exercise and making healthy choices. In-depth interviews were conducted with adolescents (aged 12-16years) to discuss their experience(s) in a referral-based fitness-nutrition program. Results from this study revealed that participants' attitude and perception of exercise shifted from apprehension to full engagement/enjoyment and were associated with individuals gaining self-confidence. These attitudes further translated to individual lifestyle changes outside of the program, illustrating the shift in motivation from external to internal. These results suggest that a potential key to enhancing physical activity and making healthy choice among overweight adolescents lie in shifting individual attitudes from a motivation to autonomous motivation in pressure-free supportive environments.
\end{abstract}

Keywords Motivation, Adolescent, Exercise, Attitude, Confidence, Obesity, Overweight

\section{Background}

As a formally recognized global epidemic ${ }^{(1,2)}$, obesity is ever present in today's society ${ }^{(3)}$. Overweight and obesity in the Canadian population has rapidly increased over time. In particular, the prevalence of has increased and obesity has increased more rapidly among certain populations including children and adolescents. For example, over the past 25 years, adolescents classified as overweight increased by $70 \%$ (to $18 \%$ ) while obesity rates grew more than three times of all Canadian children (to $9 \%$ ) ${ }^{(4)}$. The rapidly climbing rates resulted in Health Canada ${ }^{(5)}$ declaring obesity as one of three major health concerns facing children today.

Much of the research on exercise-based intervention programs has focussed on the efficacy and its use as a potential treatment for obesity. For example, a recent physical activity report card stated that only $7 \%$ of Canadian children and adolescents achieve the recommended 60 minutes of moderate-vigorous physical activity each day ${ }^{(6)}$. Compounding this trend and the observed hikes in obesity rates ${ }^{(4)}$, there is an increasing demand for direct programs and policies for obesity prevention strategies that target children and adolescents ${ }^{(3)}$. Exercise referral schemes and fitness-nutrition programs have recently become a more common method to increase physical activity. Research suggests that supervised exercise programs increase metabolic function, improve markers for glycemic control, and improve overall quality of life among overweight youth ${ }^{(7-8)}$. Moreover, it has been suggested that the benefits of these programs extend beyond physical health to potentially improving mental health, self-esteem and self-confidence (9-10). While exercise-based programs have resulted in considerable physiological and psychological benefits, the participation and compliance rates remain poor ${ }^{(11-13)}$; in particular, overweight or obese children are less physically active than normal-weight peers ${ }^{(14-16)}$.

Previous studies have shown that overweight and obese adolescents tend to have negative attitudes towards physical activity ${ }^{(17-18)}$ with motivation identified as a common barrier to successful behavioural change ${ }^{(2)}$ in the management of adolescent obesity ${ }^{(19)}$. Even though there is extensive literature on motivation and barriers to exercise, there is little 
known about why overweight or obese children are less willing than normal weight children to be involved in physical activity ${ }^{(20)}$. In this regard, Self-Determination Theory (SDT) provides insight into reasons why individuals adopt and maintain certain (health) behaviours and has been used to examine exercise and physical activity participation (21-22). According to SDT, the regulation toward physical activity can be a motivation (lacking intention to engage in physical activity), controlled motivation (being physically active under feelings of internal or external pressure); and, autonomous motivation (being physically active to improve fitness or health). SDT assumes that more controlled forms of motivation can be internalized and transformed into autonomous motivation, if the environment is supportive. For example, a supportive social -contextual environment positively effects physical activity in children ${ }^{(23-27)}$ making social support a key facilitator of behavioural changes ${ }^{(23,28)}$.

It appears that children's obesity treatment programs can increase autonomous forms of motivation towards physical activity during treatment, provided particular attention is paid to autonomy (choices), competence (feeling effective), and relatedness (socially connected) ${ }^{(22,29-32)}$. Other studies found that motivation may be thwarted by a lack of short-term rewards (2) and/or consistently effective motivators ${ }^{(33)}$, which may contribute to a less positive attitude towards exercise ${ }^{(17)}$. It is therefore crucial to explore why and how overweight and obese adolescents engage in and sustain physical activity. In particular, the purpose of this pilot study is to explore overweight adolescents' perceptions and experiences of a referral-based fitness-nutrition program which will provide better understanding of factors that influence their motivation, engagement and sustainability towards physical activity and healthy lifestyles ${ }^{(13)}$.

\section{Methods}

\section{Setting: Teens in Motion Program}

The Teens in Motion (TIM) program is a referral-based weekly fitness-nutrition program for clinically overweight adolescents (12-16 years). The aim of the TIM program is to encourage participants to be more active, to develop confidence and skills to try new activities in their school or community, and to educate them about healthy eating. The TIM program is tailored to meet the needs of clinically overweight and obese adolescents. It provides a comprehensive program including instruction on safe use of standard gym equipment with age-appropriate guidelines exposure to various cardiovascular and resistance-training techniques along with movement coordination to help build functional strength and endurance for other sports activities. Adolescents enrolled in the program are supported by
Certified Exercise Physiologists (CSEP- CEP) and kinesiology student volunteers. They are provided with the opportunity to learn and directly apply healthy lifestyle skills in a safe and judgment-free environment, advocating long term lifestyle changes instead of short-term weight loss. This study examined the experience of adolescents within the program who attended weekly 60-minute sessions of personalized exercise programs over the course of 6 months.

\section{Qualitative Interviews}

This exploratory pilot study employed a qualitative research design that included in-depth interviews to examine the perceptions and experiences of overweight or obese adolescents enrolled in the TIM program. At the start of the program session, an initial exercise assessment examined height, weight, waist circumference, body mass index (BMI), resting and exercising blood pressure, as well as rate of perceived exertion during exercise for each participant. These measures were also taken at the end of the 6-month program for comparison. Participants were purposefully selected to represent adolescents enrolled in a physical activity and nutrition programs. The criteria for selection included: attendance at TIM program; age - adolescents (12-16 years); and, diversity of gender. Recruitment methods such as posters and word of mouth were used to recruit participants. Of a total of 8 adolescents enrolled in the program (Spring 2014 session), 6 agreed to participate. This study was approved by the equitable representation by sex. University of Waterloo Research Ethics Board.

After receiving written parental consent, adolescents provided informed assent. Participating adolescents engaged in one in-depth face-to-face interview, independent of parental presence, to fully explore the perceptions and experiences of their involvement in the TIM fitness-nutrition program. The interview guide was developed by the research team and contained questions related to experiences towards exercise and physical activity; motivation, engagement and participation; and, perspectives of the program environment. SDT was used to develop questions exploring motivation, particularly to understand the role of intrinsic motivation vs. extrinsic motivation. The interview guide was pilot tested by members of the research team to ensure questions were phrased in an age-appropriate manner to gather relevant data. A trained student research assistant conducted the interviews and all interviews were audio-recorded, transcribed verbatim, and member-checked with participants for their confirmation (34). Interviews ranged in length from 30 to 45 minutes. Subsequent thematic analysis, using Word (2013), were guided by inductive and deductive approaches; that is, informed by the objectives of the research as well as the themes emerging from the interview data. 
Table 1. Clinical Measures of Adolescents Enrolled in TIM ( $n=6)$. Individual clinical measures were tracked before and after the completion of the 6-month program. Clinical markers of one female participant were not included into this table due to missing data. This data should be interpreted with caution as these markers were not adjusted for individual puberty and growth.

\begin{tabular}{|c|c|c|c|c|c|c|}
\hline & \multicolumn{2}{|c|}{ Before (December 2013/January } & \multicolumn{2}{c|}{ After (June 2014) } & \multicolumn{2}{c|}{ Net Change } \\
\hline Participant & $\begin{array}{c}\text { BMI } \\
(\mathrm{kg} / \mathrm{m} 2)\end{array}$ & $\begin{array}{c}\text { Waist } \\
\text { Circumference }(\mathrm{cm})\end{array}$ & $\begin{array}{c}\text { BMI } \\
(\mathrm{kg} / \mathrm{m} 2)\end{array}$ & $\begin{array}{c}\text { Waist circumference } \\
(\mathrm{cm})\end{array}$ & $\begin{array}{c}\text { BMI } \\
(\mathrm{kg} / \mathrm{m} 2)\end{array}$ & $\begin{array}{c}\text { Waist Circumference } \\
(\mathrm{cm})\end{array}$ \\
\hline Female, 15 years & 38.7 & 125 & 36.7 & 118.5 & -2 & -6.5 \\
\hline Female, 16 years & 28.6 & 93 & 32.1 & 101.5 & 3.5 & +8.5 \\
\hline Female, 14 years & 33 & 107 & 31 & 104.5 & -2 & -2.5 \\
\hline Male, 14 years & 32.9 & 110 & 34.3 & 34.3 & 1.4 & +6.5 \\
\hline Male, 12 years & 28.7 & 97 & 29 & 97.5 & .0 .3 & +0.5 \\
\hline
\end{tabular}

\section{Results}

The participants in the study $(\mathrm{n}=6)$ ranged in age from 12-16 years old with the average age of 14.16 years. Participants attended the program for a minimum of 6 months (December 2013 - June 2014), with an average of 34 sessions attended. All study participants had regular attendance throughout each session ( $70.8 \%$ attendance). Clinical markers were taken before and after the 6 month program to provide insight on individual progression. The average net change in Body Mass Index (BMI) and Waist Circumference were $+0.24 \mathrm{~kg} / \mathrm{m}^{2}$ and $+1.3 \mathrm{~cm}$, respectively.

\section{Thematic Analysis of Interviews}

The thematic analysis of the in-depth interviews uncovered 4 main themes: (1) Exploring Motivations; (2) Understanding Engagement and Focus; (3) Changing Perceptions of Healthy Lifestyles; and (4) Benefits of Supportive Environment. Our findings provide significant insight into how participants perceived exercise, felt motivated or de-motivated, and the extent to which the program environment impacted their lives. The central theme that structured our analysis was how motivation and engagement influenced overall experience in the program.

\section{(1) Exploring Motivations}

All adolescents in the study discussed a variety of ways they felt motivated to participate in the program. These findings suggest that motivation (to exercise) is a multi-dimensional concept that depended greatly upon environmental program context, as well as time and space. Since the TIM program is a referral-based program, all participants identified the initial drive to attend the program as external: "My doctor referred me;" and "I think it was my dietitian that told me and my Mom about it [TIM]". Most adolescents explained they had little or no desire to attend the program outside the physician referral. Adolescents identified a variety of reasons for their continued engagement; many reported feeling better physically and mentally. Over time, most participants described both the physical benefits and personal goals, as reasons for feeling motivated (Table 2a).

Participants described various they enjoyed participating in the program itself acknowledged the social, physical, and psychological benefits them from exercising: "I don't know. I just like coming here;" "To get healthier and to keep up a good mood when I am exercising," and, "I can get more muscle and more active." When asked about what feelings they associated with exercising, adolescents identified; "feeling pumped"; "more energetic"; "feeling refreshed"; and, "I think I am a fair bit more energetic now than I was before."

One adolescent articulated how they were beginning to conceptualize the relationship between exercise and health:

I do think exercise and health kind of mix together, because exercise gives you health. It is a little hard to explain. Yea, well after exercising, you feel good and you also know that you are going to be healthier afterwards too.

Most participants identified factors exercise or the program as de-motivating. In general, they most commonly identified having a "bad day" as the most frequently cited reason for not attending the program (Table $2 b$ ). In particular, participants were asked about specific exercises they disliked that may be demotivating; and, when probed further adolescents attributed their dislike to the difficulty of a particular exercise and the lack of physical ability and competence with their technique (Table 2c). Interestingly one adolescent reported that new or unfamiliar exercises were both motivators and de-motivators. More specifically, the physical "struggle" was associated with the challenge of learning a difficult exercise while also the desire to work harder in future attempts:

The side bridges ...I know my form is not really good, which makes me struggle more with it... I feel like I can't do it, because I am not doing it like right. I feel like, oh I am not going to ever get it ... but, it helps motivate me to try harder next time"

\section{(2) Understanding Engagement and Focus}

At the start of the program, most participants perceived exercise as singular activities, such as sports and gym class, and associated exercise with structured actions or activities rather than individual feelings or experiences: "Like sports ... well, I used to do basketball, so that is what pops into my 
head." Another participant described a more integrated, holistic view of exercise:

Well I thought, kind of, like usually exercise is ... it's like toning, and even with the walking, but now I see there is more like exercises I could do, but it was always either just like running, walking, elliptical, or like dumb bells, and now I see that there is like many other things that I don't need anything else with them.

A few participants reported that the strategies they employed to stay engaged and committed to exercise were primarily a result of developing a new mental space to focus on during exercising. Common among responses were attaining personal bests, and developing proper technique and form, which helped motivate them.

\section{P: I just get really focused when I am exercising.}

R: Okay. Can I ask what you are focusing on?

P: Like the proper form. I just try to reach my maximum, ...

So I ask what my time is before, and I try to like beat that by even like a few seconds

More than half of the participants talked about different methods of staying focused on the task at hand, and employing attention-distraction techniques (Table 2e), such as listening to music and thinking about personal benefits and goals as ways to increase exercise intensity without increasing physical painful symptoms.

\section{(3) Changing Attitudes towards Healthy Lifestyles}

When entering the program, most participants acknowledged feeling hesitant towards exercise, but as they developed more confidence about their abilities, their desire to exercise more regularly, increased. Most participants talked about changes in perceptions and attitudes due to increased physical strength, enhanced performance, and improved abilities to try new physical activities (Table 2f). Adolescents unanimously reported that their physical activity levels had increased since attending the program, and many participants talked about making additional individual changes to increase physical activity level outside the program, such as walking more and joining a gym. One participant specifically mentioned their change in behaviour: "Okay so sometimes, if I don't go to the gym, like I will run outside. I think before I wouldn't."
Several participants also articulated an increased awareness in nutrition and healthy lifestyle options around eating habits, particularly issues pertaining to portion sizes and food choice decisions (Table $2 \mathrm{~g}$ ).

\section{(4) Benefits of a Supportive Environment}

All participants spoke freely how important the program environment was to fostering motivation and developing confidence. In particular, participants explained the key role that volunteers and certified trainers played in encouraging their early fitness-nutrition development. A few participants talked about how tailored activities and appreciative and supportive feedback were helpful to feeling secure and sustaining motivation (Table $2 \mathrm{~h}$ ).

Most participants felt the program offered them a pressure-free environment that was safe (from discrimination), and provided meaningful connection to other teens with similar weight-related problems (Table 2i). In particular, the care and support of trainers and volunteers helped individual adolescents gain confidence and security in knowing they were being encouraged to try and choose new activities in which they had no previous experience. One participant mentioned: "Well what I like about it is like getting to know some people who have the same struggles as me, like you know like lack of exercise."

Continued attendance and competence gave participants the opportunity to develop more confidence, increase independence, and assume more individual responsibility for their physical development. Several adolescents attributed their gain in confidence to belonging to a positive social group and learning about healthy lifestyle choices which translated to individual changes in behaviour: "Well I have definitely gotten better at like doing chores and stuff. I think it has helped me in that sense of responsibility."

Most notably, participants ascribed their perceived increase in confidence to their ability "to do more". It was clear that most participants felt "better" about themselves since enrolling in the program and could see the difference to their physical and mental health. Increased confidence and enhanced self-efficacy motivated most adolescents to continue exercising and to believe in their abilities to engage in life more fully (Table $2 \mathrm{j}$ ) : It is not making me feel good about myself because of exercise. Just making me feel good about myself in general here... like I am happy, but also proud of myself at the same time... Because I know that I worked the best I could and I am going to continue to do so. 
Table 2. Quotes from study participants explaining: individual motivations (a) demotivations (b, c) to exercise; methods of engagement (d); personal changes in attitude (e) and effort towards pursuing a healthier lifestyle through exercise (f) and healthy diets (g); and the importance of a positive (h), judgment-free (i) environment to inspire confidence to do more (j). These quotes were transcribed verbatim from in-depth face-to-face interviews with study participants.

\begin{tabular}{|c|c|c|}
\hline \multicolumn{2}{|r|}{ Themes } & Quotes \\
\hline \multirow{3}{*}{$\begin{array}{l}\text { Exploring } \\
\text { Motivations } \\
\text { and } \\
\text { Demotivation }\end{array}$} & $\begin{array}{l}\text { Motivation } \\
\text { (a) Reasons to exercise }\end{array}$ & $\begin{array}{l}\text { It relieves a lot of stress } \\
\text { What makes me want to exercise? ... You know possibly future jobs that involve physical activity. } \\
\text { Like sports teams. } \\
\text { It always makes me feel better afterwards ... after a while you just feel good and more energetic } \\
\text { It makes me feel good knowing that I have got to try my best trying to make myself healthier and } \\
\text { look better }\end{array}$ \\
\hline & $\begin{array}{l}\text { Demotivation } \\
\text { (b) Bad Days }\end{array}$ & $\begin{array}{l}\text { When I am not feeling well, or something, or I didn't have a good day, I kind of feel like sluggish, } \\
\text { and I was like, okay, this day is going to be like not good, and it was discouraging, and I sort of } \\
\text { don't feel like doing anything, and like moping around. } \\
\text { Maybe there is just one of those days where everything just feels a little, how can you say, just } \\
\text { nothing goes right, and you just feel like you don't want to do anything. }\end{array}$ \\
\hline & $\begin{array}{l}\text { (c) Difficulties with } \\
\text { exercises and techniques }\end{array}$ & $\begin{array}{l}\text { Probably lunges. So I always seemed to be a little more stressful for me. I don't always enjoy them. } \\
\text { Okay, like the bosu ball, like when you step up and down. It just feels awkward. I just think I might } \\
\text { fall off of it. }\end{array}$ \\
\hline $\begin{array}{l}\text { Understanding } \\
\text { Engagement } \\
\text { and Focus }\end{array}$ & $\begin{array}{l}\text { (d) Attention-Distraction } \\
\text { Techniques }\end{array}$ & $\begin{array}{l}\text { I just try to think sometimes you know when you feel all out of breath, but sometimes I am trying to } \\
\text { think of something completely different, like a song I like, or like a show or something that I } \\
\text { thinking about trying to get my head off of being out of breath and tired, and try to think of } \\
\text { something more happy, or something. } \\
\text { Usually I just focus on the music that they have playing and in my head I just kind of sing along and } \\
\text { do it over and over again. } \\
\text { Well thinking of my goals at the end, like how I want to be, and just thinking how healthier I can be } \\
\text { at the end, and just feeling better about myself. } \\
\text { Well sometimes I always feel some tiredness at the end, but also after a while I feel that I know that } \\
\text { I exercised and it makes me feel good afterwards" }\end{array}$ \\
\hline \multirow{4}{*}{$\begin{array}{l}\text { Changing } \\
\text { Attitudes } \\
\text { towards } \\
\text { Healthy } \\
\text { Lifestyles }\end{array}$} & $\begin{array}{l}\text { (e) Shifts in Attitudes } \\
\text { towards Exercise }\end{array}$ & $\begin{array}{l}\text { I used to like hate exercising. So I wouldn't do it, and now like I enjoy it a lot more and I am slowly } \\
\text { starting to exercise more...[Now] It is actually me that says, hey we are going to the gym! } \\
\text { I think it is gotten me to be a bit more open to other activities. }\end{array}$ \\
\hline & $\begin{array}{l}\text { (f) Individual changes to } \\
\text { exercise more }\end{array}$ & $\begin{array}{l}\text { Yea, I can say, because when we were doing walks before, it was kind of on and off, but lately we } \\
\text { seem to be actually going a lot longer, and we know that we want to try and get out on a daily basis. } \\
\text { I think it has gone like more than it has before, like now I am walking more. I am going out more, } \\
\text { and I am doing more on my own, other than before, when I am was like okay, whatever, I will do it } \\
\text { this day, but then I procrastinated, but now I feel like I am actually sticking to it, and doing it more } \\
\text { often. So this helps keep me on track, because it is once a week, but other than that, I go more. }\end{array}$ \\
\hline & $\begin{array}{c}\text { (g) Personal changes in } \\
\text { nutrition }\end{array}$ & $\begin{array}{l}\text { I used to eat like a whack of carbs, and that would be all I eat, but now like I try to incorporate more } \\
\text { fruits and vegetables and protein. } \\
\text { Well definitely snacking. Like again with the chips, and I am more going over to fruits and veggies. }\end{array}$ \\
\hline & $\begin{array}{l}\text { (h) Importance of positive } \\
\text { and encouraging } \\
\text { environment }\end{array}$ & $\begin{array}{l}\text { This is like more about the people always have like a positive attitude towards you. That is probably } \\
\text { the big thing...Because they stay positive, and they just like encourage you to stay positive no } \\
\text { matter how hard it is for you. } \\
\text { Probably the people, because the people really make me feel good. Make me feel like it is a safe and } \\
\text { good environment. To know that I can just do my best without having anyone you know trying to } \\
\text { tell me you are not doing it right, or do it even harder, but at the same time telling me to do it harder, } \\
\text { but in a good way to try and do my best }\end{array}$ \\
\hline \multirow{2}{*}{$\begin{array}{l}\text { Benefits of a } \\
\text { Supportive } \\
\text { Environment }\end{array}$} & $\begin{array}{l}\text { (i) Judgment-free } \\
\text { atmosphere }\end{array}$ & $\begin{array}{l}\text { I knew it was going to be like fun, and the atmosphere is encouraging. It is supportive, and if it } \\
\text { weren't for this, I probably wouldn't be working out as often. } \\
\text { I know like that at school kind of, sometimes it is difficult because there are so many people, and it } \\
\text { is kind of like this complex, like all the eyes watching and everything, and sometimes even in } \\
\text { school you have criticism. So I feel like it is easier here, because nobody talks or anything about, } \\
\text { and we are all like, we are friends with each other. So it is easier. }\end{array}$ \\
\hline & $\begin{array}{l}\text { (j) Self-efficacy and ability } \\
\text { to "do more" }\end{array}$ & 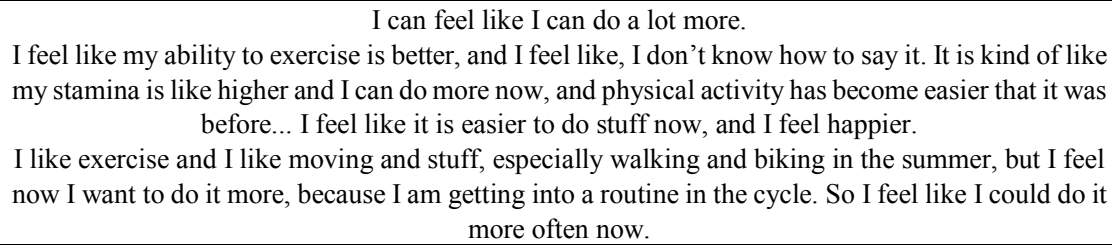 \\
\hline
\end{tabular}




\section{Discussion}

The objective of this exploratory qualitative pilot study was to investigate the experiences of adolescents enrolled in a referral-based fitness nutrition program. With a particular focus on motivation and engagement, our findings provide insights into the ways adolescents' motivation towards physical activity and awareness of healthy lifestyle choices may change over time. The study results showed that adolescents' initial feelings of apprehension towards physical activity transformed over time to full engagement, as they learned new skills and gained more confidence in their capabilities. These findings support other research that has shown that autonomous types of motivation (being physically active to improve fitness or health or the activity is enjoyable) are associated with greater participation in physical activity ${ }^{(35-39)}$.

Our findings also showed that teens benefited from the opportunity of engaging in a range of exercise choices as well as relevant nutrition information to identify and decide on healthy lifestyle choices. This finding supports previous studies that showed having choices in activities is more beneficial than only following a specific prescription ${ }^{(40-41)}$. Participants in our study appreciated and enjoyed the variety of activities in the program and began to independently initiate new activities outside the program, which in turn increased their engagement and satisfaction in physical activity. Other research has shown that autonomy of choice helps motivate and engage obese adolescents to exercise ${ }^{(10,}$ 35). With regards to SDT, our study results suggest that a supportive program environment that fosters competence and social relations meant adolescent motivations towards physical activity can shift from being unengaged (a motivation) to being physically active, with a new purposeful desire to improve health (autonomous motivation).

As a referral-based program, initial motivation was ostensibly externally driven, in which some participants reported feeling hesitation toward physical activity. Also, some adolescents initially conceived physical activity quite narrowly and in singular ways (e.g. gym class or sport) rather than viewing it holistically in terms of being linked to healthy lifestyles. However, with both time and through the development of confidence in their abilities, participants associated their change in attitude and understanding of physical activity and health to their ongoing shift in motivation - initially driven by extrinsic forces (based on physician referral) to intrinsic forces (self-initiated goals). For example, adolescents reported feeling enjoyment physical activity in the program and attributed this to feeling healthier and stronger. Furthermore, participants discussed their appreciation for the variety of activities in the program. Similar to other studies ${ }^{(10,42-43)}$, we found that personal enjoyment in exercise was consistently associated with improved attendance and increased engagement during program activities. Although participants described different aspects of the program that they enjoyed, they openly discussed their satisfaction about developing strength and competence. This result in and of itself, addresses a major barrier to exercise and motivation that is commonly seen in overweight and obese adolescents ${ }^{(10)}$.

Overweight and obese adolescents experience a range of barriers to participation in physical activity ${ }^{(44)}$. For example, environmental and interpersonal circumstances can reinforce negative self-perceptions at a critical point in their psychosocial development. Participants in this study openly discussed the positive influence that the program environment had on their confidence, making special note of self-efficacy, and their ability to do more. These findings suggest that participants benefited from the meaningful connections they developed with other teens who had similar weight related problems. Other research has shown that a perceived lack of athletic ability relative to peers is a major barrier and negatively influences participation in physical activity ${ }^{(45)}$. Our research suggests that the program environment greatly supported participant initiatives, provided adolescents' with relevant information for changing lifestyle behaviours, and employed appreciative supportive language that fostered motivation and engagement towards physical activity. This finding is supported by other research ${ }^{(46-48)}$ that found activities with sufficient instruction and positive feedback, that were tailored to capabilities for obese adolescents generated a sense of competence. ${ }^{(18,46-48)}$.

To effectively build confidence in the physical activity, it is imperative to provide a supportive and encouraging environment. It has previously been demonstrated that constant encouragement and motivation are necessary for obese adolescents to exercise ${ }^{(2)}$. Participants in the present study spoke openly about the importance of a pressure-free environment and the encouragement of dedicated trainers and volunteers to support their early development. Our findings indicate that to support health behaviour changes, it is imperative to provide a social- contextual environment that builds in activities tailored to capabilities, provides appropriate feedback, and encourages equitable interactions with peers. Thus, providing obese and overweight adolescents a judgment-free and supportive environment is necessary to ensure psychological security and ease when exercising. This should be taken into account when designing similar programs.

As a predictor of future health decisions ${ }^{(17)}$, instilling a positive attitude toward physical activity facilitates healthy behavior ${ }^{(17-18)}$. Participants in this study discussed in various ways that the conditions helped shift their motivation to defuse any negative attitudes or perceptions towards exercise in order to view physical activity and healthy lifestyle choices as reachable goals. It is thus of greater importance to provide and develop consistent and effective motivators ${ }^{(19,33)}$ for physical activity to facilitate the development of a positive attitude to physical activity (33) for healthy behaviours ${ }^{(2)}$. After thorough discussion and analysis, we believe that participants noted change in motivation impacted their attitude towards exercise and ultimately their 
perception of exercise and overall health. Our findings indicate that to assist health behaviour changes, it is imperative to find ways to foster environments that nurture positive attitude and confidence towards physical activity. This can be facilitated by individual enjoyment of the physical activity and knowledge of exercise-induced benefits, which can be achieved by including activities participants enjoy in a supportive, pressure-free environment. The reported shift in motivation can (2) facilitated by developing personalized short-term goals and providing a fun and enjoyable experience ${ }^{(10)}$.

The limitations of this study include those inherent to qualitative research and those related to study sample. While this research may contribute to our understanding of the factors that influence adolescent motivation, engagement and sustainability towards physical activity and healthy lifestyles, its generalizability across other programs is limited given one referral-based program. The sample for this pilot study was relatively small, purposefully selected, and not representative of the all overweight or obese adolescents. The sample was chosen from adolescents engaged and enrolled in one fitness-nutrition program; so, it is unknown how unengaged overweight and obese adolescents from other types of prevention programs would respond. However, results from this study provide insights into how adolescents experience and are motivated to engage in physical activity in particular environmental conditions. Future research, therefore, needs to be conducted across cultural groups and in a variety of fitness- nutrition intervention programs in order to strengthen the validity of the theories and methods used in this study.

\section{Implications for Future Research}

The findings have a number of implications for overweight and obese adolescents. One of the most compelling implications for this population is an understanding of the socio-contextual conditions that foster confidence, build competence and enhance motivation for developing long-term physical activity engagement. In particular, it is important to design fitness-nutrition programs where activities are tailored to individual capabilities, where participants are encouraged to set realistic goals and learn self-management skills.

These results provide a preliminary framework for understanding what context means to adolescents and highlights the difference in how they are motivated. Understanding these differences may be an effective way of informing interventional efforts towards attitudes towards physical activity and healthy lifestyles.

Finally, it is anticipated that these research results will advance our understanding of why and how adolescents engage in and sustain their involvement in physical activity and provide insights into how they construct motivation within specific environments.

\section{Acknowledgements}

\author{
Scensor Inc, UW Fitness
}

\section{REFERENCES}

[1] Caballero B. The global epidemic of obesity: an overview. Epidemiol Rev. 2007; 29: 1-5.

[2] Murtagh J, Dixey R, Rudolf M. A qualitative investigation into the levers and barriers to weight loss in children: Opinions of obese children. Arch Dis Child. 2006; 91: 920-3.

[3] Lobstein T, Baur L, Uauy R. Obesity in children and young people: A crisis in public health. Obes Rev. 2004; 5: 4-104.

[4] Shields, M. Measured Obesity: Overweight Canadian children and adolescents. Nutrition: Findings from the Canadian Community Health Survey, Statistics Canada. 2005.

[5] Canadian Guidelines for body weight classification in adults. Ottawa: Health Canada. 2003.

[6] Tremblay MS, Warburton DE, Janssen I, et al. New Canadian physical activity guidelines. Appl Physiol Nutr Metab. 2011; 36: 36-46.

[7] Bluher S, Petroff D, Wagner A, et al. The one year exercise and lifestyle intervention program KLAKS: Effects on anthropometric parameters, cardiometabolic risk factors and glycemic control in childhood obesity. Metabolism. 2014; 63: 422-30.

[8] Meucci M, Cook C, Curry CD, Guidetti L, Baldari C, Collier SR. Effects of supervised exercise program on metabolic function in overweight adolescents. World J Pediatr. 2013; 9: 307-11.

[9] Thompson RL, Thomas DE. A cross-sectional survey of the opinions on weight loss treatments of adult obese patients attending a dietetic clinic. Int J Obes Relat Metab Disord. 2000; 24:164-70.

[10] Daley AJ, Copeland RJ, Wright NP, Wales JK. 'I can actually exercise if I want to; it isn't as hard as I thought': A qualitative study of the experiences and views of obese adolescents participating in an exercise therapy intervention. $J$ Health Psychol. 2008; 13: 810-9.

[11] Skelton JA, Beech BM. Attrition in paediatric weight management: A review of the literature and new directions. Obes Rev. 2011; 12: e273-81.

[12] Skelton JA, Irby MB, Beech BM, Rhodes SD. Attrition and family participation in obesity treatment programs: Clinicians' perceptions. Acad Pediatr. 2012; 12: 420-8.

[13] Williams NH, Hendry M, France B, Lewis R, Wilkinson C. Effectiveness of exercise- referral schemes to promote physical activity in adults: Systematic review. Br J Gen Pract. 2007; 57: 979-86.

[14] Janssen I, Katzmarzyk PT, Boyce WF et al. Comparison of overweight and obesity prevalence in school-aged youth from 34 countries and their relationships with physical activity and dietary patterns. Obes Rev. 2005;6:123-32. 
[15] Haerens L, Deforche B, Maes L, Cardon G, De Bourdeaud-huij I. Physical activity and endurance in normal weight versus overweight boys and girls. $J$ Sports Med Phys Fitness. 2007;47:344-50.

[16] Deforche B, Cardon G, De Bourdeaudhuij I. Objectively measured physical activity, physical activity related personality and body mass index in 6 to 10 year old children. Int J Behav Nutr Phys Act. 2009;14(6):25.

[17] Lindelof A., C. V. Nielsen, and B. D. Pedersen. A qualitative, longitudinal study exploring obese adolescents' attitudes toward physical activity. J Phys Act Health. 2013; 10: 113-21.

[18] Deforche BI, De Bourdeaudhuij IM, and Tanghe AP. Attitude toward physical activity in normal-weight, overweight and obese Adolescents. J Adolesc Health 2006; 38: 560-8.

[19] Story MT, Neumark-Stzainer DR, Sherwood NE, et al. Management of child and adolescent obesity: Attitudes, barriers, skills, and training needs among health care professionals. Pediatrics. 2002; 110: 210-4.

[20] Hwang J, Kim YH. Physical activity and its related motivational attributes in adolescents with different BMI. Int J Behav Med. 2011; 20:106-13.

[21] Deci EL, Ryan RM. Intrinsic motivation and self-determination in human behavior. New York, NY: Plenum Press; 1985.

[22] Ryan RM, Deci EL. Self-determination theory and the facilitation of intrinsic motivation, social development, and well-being. Am Psychol. 2000; 5: 68-78.

[23] Robinson TN. Behavioural treatment of childhood and adolescent obesity. Int J Obes. 1999;23(Suppl. 2):S52-7.

[24] Wilson DK, Evans AE, Williams J, Mixon G, Sirard JR, Pate R. A preliminary test of a student-centered intervention on increasing physical activity in underserved adolescents. Ann Behav Med. 2005;30:119-24.

[25] Fortier MS, Sweet SN, O"Sullivan TL, Williams G. A self-determination process model of physical activity adoption inthe context of a randomized controlled trial. Psych Sport Exerc. 2007;8:741-57.

[26] Edmunds J, Ntoumanis N, Duda, J. Testing a self-determination theory-based teaching style intervention in the exercise domain. Eur J Social Psych; 2008,38:375-88.

[27] Chatzisarantis NL, Hagger MS. Effects of an intervention based on self-determination theory on self-reported leisure-time physical activity participation. Psychol Health. 2009; 24:29-48.

[28] Williams GC, Mcgregor HA, Sharp D et al. Testing a self-determination theory intervention for motivating tobacco cessation: supporting autonomy and competence in a clinical trial. Health Psychol. 2006; 25:91-101.

[29] Ryan RM. Psychological needs and the facilitation of integrative processes. J Personality. 1995;63:397-428.

[30] Deci EL, Ryan RM. The "What" and "Why" of goal pursuits: human needs and the self- determination of behavior. Psycholog Inq. 2000; 11:227-68.

[31] Standage M, Duda JL, Ntoumanis N. A model of contextual motivation in physical education: using constructs from self-determination theory and achievement goals to predict physical activity intentions. $J$ Educ Psych. 2003; 91: 97-110.

[32] Verloigne M, Bourdeauhuij ID, Tanghe A, et al. Self-determined motivation towards physical activity in adolescents treated for obesity: an observational study. Int $J$ Behav Nutr Phys Act. 2011; 8: 97-108.

[33] Chung RJ, Sherman L, Goodman E, Bickham DS, Rich M. Exploring the perspectives of obese adolescent girls. Qual Health. Res. 2013; 23: 1369-76.

[34] Charmaz K. Constructing Grounded Theory: A Practical Guide Through Qualitative Analysis. Thousand Oaks, CA: Sage; 2006.

[35] Edmunds J, Ntoumanis N, Duda JL. A self determination theory in the exercise domain. $J$ Appl Soc Psych. 2006;36:2240-65.

[36] Gillison FB, Standage M, Skevington SM. Relationships among adolescents" weight perceptions, exercise goals, exercise motivation, quality of life and leisure-time exercise behaviour: a self-determination theory approach. Health Educ Res. 2006;21:836-47.

[37] Shen B, McCaughtry N, Martin J. The influence of self-determination in physical education on leisure-time physical activity behavior. Res Q Exerc Sport. 2007;78:32838 .

[38] Zhang T. Relations among school students" self-determined motivation, perceived enjoyment, effort, and physical activity behaviors. Percept Mot Skills. 2009;109:783-90.

[39] Taylor IM, Ntoumanis N, Standage M, Spray CM. Motivational predictors of physical education students" effort, exercise intentions, and leisure-time physical activity: a multilevel linear growth analysis. J Sport Exerc Psychol. 2010;32:99-120.

[40] Epstein LH, Wing RR, Koeske R, Ossip D, Beck S. A comparison of lifestyle change and programmed aerobic exercise on weight and fitness changes in obese children. Behav Ther. 1982;13:651-65.

[41] Dunn, Andrea L., Ross E. Andersen, and John M. Jakicic. "Lifestyle physical activity interventions: history, short-and long-term effects, and recommendations." American journal of preventive medicine 15.4 (1998): 398-412.

[42] Faith MS, Leone MA, Ayers TS, Heo M, Pietrobelli A. Weight criticism during physical activity, coping skills, and reported physical activity in children. Pediatrics. 2002; 110: e23

[43] Tsang TW, Kohn MR, Chow CM, Singh MF. Self-perception and attitude toward physical activity in overweight/obese adolescents: The "Martial Fitness" Study. Res Sports Med. 2013; 21: 37-51.

[44] Stankov I, Olds T, Cargo M. Overweight and obese adolescents: what turns them off physical activity? Int $J$ Behav Nutr Phys Act.2012; 9: 53-68.

[45] Hoefer WR, McKenzie TL, Sallis JF, Marshall SJ, Conway TL. Parental provision of transportation for adolescent physical activity. Am J Pre Med. 2001; 21:48-51.

[46] Silva MN, Markland D, Minderico CS, et al. A randomized controlled trial to evaluate self-determination theory for exercise adherence and weight control: rationale and 
intervention description. BMC Public Health. 2008; 8:234-47.

[47] Lim BSC, Wang JCK. Perceived autonomy support, behavioural regulations in physical education and physical activity intention. Psychol Sport Exerc. 2009; 10:52-60.

[48] Deforche B, Haerens L, De Bourdeaudhuij I. How to make overweight children exercise and follow the recommendations. Int J Pediatr Obes. 2011; 6 Suppl 1, 35-41. 